\title{
Development of a Miniaturized Automatic Excavator with Time-Varying Sliding Mode Controller
}

\author{
Jeongju Choi ${ }^{1^{*}}$ \\ ${ }^{1}$ Technical Center for High-Performance Valves, Dong-a University \\ 시변 슬라이딩 모드 제어기를 이용한 모형 자동 굴삭기 개발 \\ 최정주 ${ }^{*}$ \\ ${ }^{1}$ 동아대학교 고기능성밸브기술지원센터
}

\begin{abstract}
These excavators have been widely used due to their flexibility in handing various tasks via simple changes of their attachments. Since the performance of manually-operated excavators heavily depend on the operators' skill level, there is a strong need for developing automatic excavators in the industry. In order to achieve such goals, exiting approaches have studied direct modification of existing hydraulic systems in the excavator for feed back control of each link. This paper presents a miniaturized automatic excavator that can be used for the development and demonstration of advanced control algorithm for excavators under a safer environment with reduced cost. Two PCs were installed and connected to the excavator through wireless communications for its control and monitoring. Tracking control of each link using a time varying sliding mode controller was performed through experiments on the developed system to demonstrate its ability.

요 약 굴삭기는 끝단의 작업 장치를 바꿈으로써 다양한 작업을 수행할 수 있어 다양한 분야에서 널리 사용되고 있 다. 그러나 작업자의 조작에 의해 작동되는 굴삭기는 작업자의 숙련도에 따라 그 작업 능률이 차이가 나게 되므로 자동 굴삭기 시스템에 대한 요구가 증가하고 있다. 본 논문에서는 모형 굴삭기를 이용하여 자동 굴삭기 시스템을 제 작하였다. 제작된 모형 굴삭기 시스템의 구동을 위해서 두 대를 컴퓨터를 이용하였다. 한 대의 컴퓨터는 작업 지령을 전달하기 위해 사용하고 다른 한 대의 컴퓨터는 굴삭기의 피드백 제어를 위해 이용하였다. 두 컴퓨터 사이의 데이터 는 무선 통신을 이용하였다. 굴삭기의 피드백 제어시스템 구성을 위해서는 시변 슬라이딩 모드 제어기를 이용하여 구 성하고 실험을 통해 제안된 모형 굴삭기의 성능을 검증하였다.
\end{abstract}

Key Words : Excavator, Tracking Control, Sliding Mode Control

\section{Introduction}

Excavators are widely used in construction sites, forestry and mining industries due to their high throughput and adaptability to various tasks via replacement of their attachments. Even though the hardware performance of excavators has improved in general, their work efficiency mainly depends on the operator's skill levels. However, the repeated joystick operations can lead to operators' fatigue and lower their work efficiency. Therefore, the demand for automatic excavator systems has steadily increased leading to active research in this area. The main issue with an automatic excavator centers around building a proper closed-loop system to control each link of the excavator which is driven by a hydraulic system. Optimal design of each part's shape for performance improvement and analysis of the power system in a hybrid hydraulic excavator were

This work was supported by Technical Center for High Performance Valves Form the Regional Innovation Center(RIC) Program of the Ministry of Knowledge Economy(MKE), Korea.

${ }^{*}$ Corresponding Author : Choi, Jeongju(jchoi72@dau.ac.kr) 
investigated by [1][2]. For robust tracking control of the hydraulic system in the excavator, control of the hydraulic single-rod cylinder using an electro hydraulic manipulator was studied [3]. On the other hand, soft- computing techniques such as neural networks and fuzzy control systems were adopted to control each link of the excavator without requiring its mathematical model [4][5]. However, the implementation of such systems tends to demand a large number of computations whereas a mathematical proof of their stability cannot be obtained with ease. Development of an automatic excavator usually involves modifying the hardware of an existing excavator and designing the control algorithm for autonomous run of the modified system. The autonomous excavator system in[6] was developed, for example, by modeling a CEE(combat engineer excavator) based on a generalized Newton method and by designing an observer for estimation of unknown model parameters. Other examples include the LUCIE (Lancaster University computerized intelligent excavator) in [7] and a system based on a nonlinear simulation model using MATLAB/SIMULINK in [8].

During the development of a control scheme for the automatic excavator, it would be ideal to test the controller with an actual excavator. However, experimenting with an actual excavator is hampered by many practical difficulties and safety concerns. Since the stability of the newly developed algorithm and hardware structure cannot be fully guaranteed, operating an excavator under such a new control scheme usually involves both safety and economic issues.

This paper presents the development of a miniaturized pneumatic excavator system with which newly developed control algorithm and hardware can be experimented economically under a safe environment in the laboratory. This miniaturized excavator will become a test-bed for developing the automatic hydraulic excavator. The control hardware of the miniaturized excavator is implemented on two separate computers for control and monitoring functions, respectively. The control module performs data acquisition and communications for remote-controlling of the excavator. In contrast, the monitoring computer observes the state of each link. The controller for operating each link of the excavator relies on the sliding mode control with time varying sliding surface. The designed sliding surface is designed with considering the position of the initial state on sliding surface phase.

\section{Miniaturized Pneumatic Excavator}

A typical excavator has three links for the boom, arm and bucket which are controlled by the operator's manipulation of a joystick. The joystick motion controls the flow and pressure of the operational fluid in the hydraulic circuit. In order to develop the automatic excavator system, a feedback control loop should be attached to the excavator. This is commonly accomplished by modifying the existing hydraulic circuit. The excavator links are driven by hydraulic actuators whose operating fluid is controlled by the $\mathrm{MCV}$ (main control valve). For automatic excavators, this hydraulic circuit is modified by installing an additional pressure control valve which can control the pilot pressure and fluid flow of the MCV[9]. This additional hydraulic valve is controlled by a joystick or through computer interface. Another approach is to develop an individual hydraulic circuit for controlling each link of the excavator.

In this study, an individual operating circuit was developed for each link of the excavator as shown in Fig. 1. Considering the small size of the excavator, pneumatic single rod cylinders instead of hydraulic actuators were installed. The structure of the developed system is similar to the real excavator system except for its pneumatic operating circuit and control device instead of hydraulic ones. Each of the arm and bucket links is driven by a single rod cylinder whereas the boom link is equipped with two cylinders since it tends to require more torque. In the pneumatic circuit shown in Fig. 1, a proportional pressure solenoid control valve and a relief valve with a maximum limited pressure of 20 [bar] are used for controlling each link.

The operating ranges of boom and arm links are given by $35^{\circ}<\theta_{1}<85^{\circ}$ and $30^{\circ}<\theta_{2}<140^{\circ}$, respectively. Fig. 2 shows the over all experimental setup while Fig. 3 shows the kinetic coordinates of the developed excavator. In order to monitor the orientation of each link, a potentiometer-type encoder was attached to each joint. Since the output from the encoder is an analog voltage, the relationship between the output voltage and joint 
angle should be obtained through a calibration experiment. Such calibration data are depicted in Fig.4. Based on the experimental data, a linear first degree equation was obtained as follows:

$$
\text { degree }=30.77 \times \text { voltage }+4.47
$$

More detailed specifications of the developed pneumatic excavator system are listed in Tables 1 and 2 . In order to setup the wireless communication, a HM-TR wireless module with a working frequency of $869 \mathrm{MHz}$ was installed whereas a serial port with a baud rate of 9600 was used for transferring additional data.



[Fig. 1] Schematic of the pneumatic circuit for the developed excavator



[Fig. 2] Appearance of pneumatic excavator

[Table 1] Physical specification of the pneumatic excavator

\begin{tabular}{|c|c|c|c|}
\hline Parts & Weight & Parts & Length \\
\hline Boom & $3.38[\mathrm{~kg}]$ & 11 & $573[\mathrm{~mm}]$ \\
\hline Arm & $2.43[\mathrm{~kg}]$ & 12 & $235[\mathrm{~mm}]$ \\
\hline Bucket & $0.94[\mathrm{~kg}]$ & & \\
\hline
\end{tabular}

[Table 2] Specification of various equipments

\begin{tabular}{|l|l|l|}
\hline \multicolumn{1}{|c|}{ Parts } & \multicolumn{1}{|c|}{ Model } & \multicolumn{1}{c|}{ Specification } \\
\hline $\begin{array}{l}\text { Angular } \\
\text { sensor }\end{array}$ & $\begin{array}{l}\text { JT 30-120- } \\
500\end{array}$ & $\begin{array}{l}0 \sim 10[\mathrm{~V}] \\
0 \sim 360[\text { degree] }\end{array}$ \\
\hline $\begin{array}{l}\text { Pneumatic } \\
\text { cylinder }\end{array}$ & Festo DSAS & $\begin{array}{l}\text { Boom stroke:60[mm] } \\
\text { Arm stroke:110[mm] } \\
\text { Bucket stroke:80[mm] }\end{array}$ \\
\hline $\begin{array}{l}\text { Proportional } \\
\text { pressure } \\
\text { control } \\
\text { valve }\end{array}$ & MPPES-3-1 & $\begin{array}{l}\text { Input voltage 0 10[V], } \\
\text { Output pressure 0 8[bar] }\end{array}$ \\
\hline DAQ card & $6036 \mathrm{E}$ & $\begin{array}{l}\text { DIO : 4channels } \\
\text { AO : 2 channel }\end{array}$ \\
\hline
\end{tabular}

Through the wireless communication, the reference tracking command and the data access confirmation signals were transmitted. This wireless communication setup has a room for addition of a vision system which, when installed, would be helpful for operating the unmanned automatic excavator in a hazardous environment. The remote-control system was implemented based on two computers. One PC controls the motion of the excavator while the other PC monitors the excavator state. The monitoring PC operates in either feedbackcontrol mode or open-loop-jog mode. In the jog mode, the operator can directly manipulate the voltage input $(0 \sim 10 \mathrm{~V})$ to the flow control valve. In the feedback mode, the reference command is off-line transferred to the control PC. After receiving the command signal, the control PC sends a confirmation to the monitoring PC and initiates the feedback control works on receipt of another confirmation from the monitoring PC. The control PC controls each link of the excavator and communicates with the monitoring PC. The communication and control logic were coded by LabView software version 7.1. on the two PCs.

Computer-interfacing for controlling each pneumatic cylinders was set up using a PCI-6036E DAQ board by National Instrument Corporation. This DAQ board provides 2 analog outputs and 8 channels DIO. The analog outputs channels were used for controlling the boom and arm links. A schematic diagram of the remote-control system is shown in Fig. 5 while Fig. 6 shows the control and monitoring layouts of the PCs. 


\section{Tracking control system design}

The dynamics of the miniature excavator is expressed as follows:

$$
M(\theta) \ddot{\theta}+V(\theta, \dot{\theta})+G(\theta)+d=\tau
$$

where $\theta=\left[\begin{array}{ll}\theta_{1} & \theta_{2}\end{array}\right]^{T}$ is the angular displacement, $\tau$ is the control input torque, $d$ is disturbance and $M(\theta)$, $V(\theta, \dot{\theta})$ and $G(\theta)$ are expressed as follows:[3]

$$
\begin{aligned}
& M(\theta)=\left[\begin{array}{ll}
M_{11} & M_{12} \\
M_{21} & M_{22}
\end{array}\right], V(\theta, \dot{\theta})=\left[\begin{array}{l}
V_{1} \\
V_{2}
\end{array}\right], \\
& G(\theta)=\left[\begin{array}{l}
G_{1} \\
G_{2}
\end{array}\right], \\
& M_{11}=l_{2}^{2} m_{2}+2 l_{1} l_{2} m_{2} \cos \left(\theta_{2}\right)+l_{1}^{2}\left(m_{1}+m_{2}\right), \\
& M_{12}=M_{21}=l_{2}^{2} m_{2}+l_{1} l_{2} m_{2} \cos \left(\theta_{2}\right), M_{22}=l_{2}^{2} m_{2}, \\
& V_{1}=-m_{2} l_{1} l_{2} \sin \left(\theta_{2}\right) \dot{\theta}_{2}^{2}-2 m_{2} l_{1} l_{2} \sin \left(\theta_{2}\right) \dot{\theta}_{1} \dot{\theta}_{2}, \\
& V_{2}=m_{2} l_{1} l_{2} \sin \left(\theta_{2}\right) \dot{\theta}_{1}^{2}, \\
& G_{1}=m_{2} l_{2} g \cos \left(\theta_{1}+\theta_{2}\right)+\left(m_{1}+m_{2}\right) l_{1} g \cos \left(\theta_{1}\right) \\
& G_{2}=m_{2} l_{2} g \cos \left(\theta_{1}+\theta_{2}\right) .
\end{aligned}
$$

The state vector is selected as

$$
x=\left[\begin{array}{ll}
x_{1} & x_{2}
\end{array}\right]^{T}
$$

where

$$
x_{1}=\theta=\left[\begin{array}{ll}
\theta_{1} & \theta_{2}
\end{array}\right]^{T}, x_{2}=\dot{\theta}=\left[\begin{array}{ll}
\dot{\theta}_{1} & \dot{\theta}_{2}
\end{array}\right]^{T} \text {. }
$$



[Fig. 3] Kinetic coordinate of the pneumatic excavator system

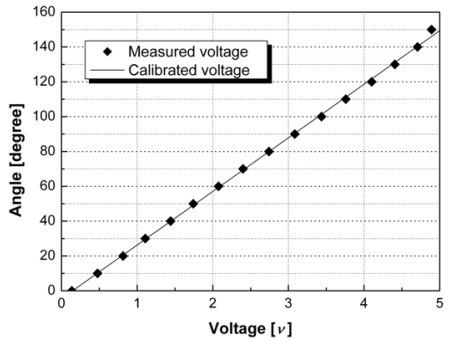

[Fig. 4] Calibration data for the angular sensor



[Fig. 5] Schematic diagram of the remote control system

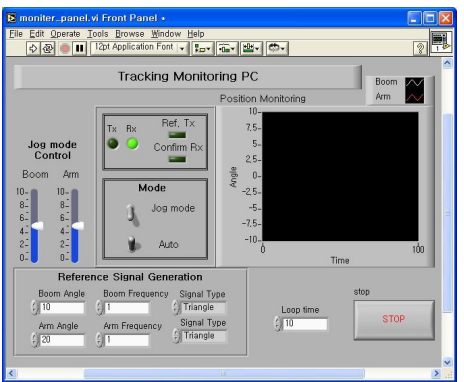

(a) User-interface of the monitoring $\mathrm{PC}$



(b) User-interface of the control PC

[Fig. 6] Layout of the monitoring and control PCs 
To design a time-varying sliding mode controller, the tracking error is defined as follows:

$$
e=\left[\begin{array}{ll}
e_{1} & e_{2}
\end{array}\right]^{T}=x_{d}-x
$$

where $x_{d}$ is the desired state, and $x$ is the system state that is the position vector. The time-varying sliding function is defined as follows:

$$
s(x, t)=\left[\begin{array}{ll}
s_{1} & s_{2}
\end{array}\right]^{T}=\dot{e}+\Lambda(t) e+\mu(t)
$$

where the slope of the sliding surface $\Lambda(t)$ is expressed as

$$
\Lambda(t)=\left[\begin{array}{cc}
\lambda_{1}(t) & 0 \\
0 & \lambda_{2}(t)
\end{array}\right]
$$

where

$$
\lambda_{i}(t)=\left\{\begin{array}{ll}
\lambda_{0 i}+\lambda_{g i} t & 0 \leqq t<t_{f i} \\
\lambda_{f i} & t \geqq t_{f i}
\end{array}, i=1,2\right.
$$

and the translational distance $\mu(t)$ is expressed as

$$
\mu(t)=\left[\mu_{1}(t) \mu_{2}(t)\right]^{T}
$$

where

$$
\mu_{i}(t)=\left\{\begin{array}{ll}
\mu_{0 i}+\mu_{g i} t & 0 \leqq t<t_{f i} \\
\mu_{f i} & t \geqq t_{f i}
\end{array}, i=1,2\right.
$$

When the initial state of the error $\left(e_{i}(0), \dot{e}_{i}(0)\right)$ is located in the 1 st or the 3rd quadrant in the phase plane, the parameters of the time-varying sliding surface are obtained as

$$
\begin{aligned}
& \lambda_{0, i}=0, \quad \lambda_{g i}=\lambda_{g i}=\lambda_{f i} / t_{f i}, \quad i=1,2 \\
& \mu_{0 i}=-\dot{e}_{i}(0), \quad \mu_{g i}=\dot{e}_{i}(0) / t_{f i}, \quad i=1,2
\end{aligned}
$$

When the initial state of the error is located in the 2 nd or the 4th quadrant in the phase plane, the parameters of the time-varying sliding surface are obtained as

$$
\begin{aligned}
& \lambda_{0, i}=-\dot{e}_{i}(0) / e_{i}(0), \lambda_{g i}=\left(\lambda_{f i}-\lambda_{0 i}\right) / t_{f i} \\
& \mu_{0 i}=0, \mu_{g i}=0, i=1,2
\end{aligned}
$$

The control input is selected as follows:

$$
u=u_{e q}^{n}+M D s+K s a t(s)
$$

where the proportional gain $D$ and the switching gain $K$ are expressed as

$$
D=\left[\begin{array}{cc}
d_{1} & 0 \\
0 & d_{2}
\end{array}\right], K=\left[\begin{array}{cc}
k_{1} & 0 \\
0 & k_{2}
\end{array}\right]
$$

The saturation function $\operatorname{sat}(s)$ is expressed as

$$
\operatorname{sat}(s)=\left[\operatorname{sat}\left(s_{1}\right) \operatorname{sat}\left(s_{2}\right)\right]^{T}
$$

where

$$
\operatorname{sat}\left(s_{i}\right)= \begin{cases}1, & \text { if } s_{i} \geqq \phi_{i} \\ s_{i}, & \text { if }-\phi_{i} \leqq s_{i}<\phi_{i} \quad i=1,2 \\ -1, & \text { if } s_{i} \longleftarrow \phi_{i}\end{cases}
$$

and $\phi_{i}$ is the thickness of the boundary layer. The nominal equivalent control input $u_{e q}^{n}$ is obtained as

$$
u_{e q}^{n}=M\left[\ddot{x_{d}}+\dot{\Lambda e}+\dot{\Lambda} e+\dot{\mu}\right]+V+G
$$

In the implemented sliding mode control, sat $(s)$ is linearized within a small thickness of the boundary layer $\phi_{i}$ to avoid excessive switching. The switching gain $K$ is treated as a constant because the magnitude of the switching term is small compared with the proportional term and the variation of $M$ is not so large.

\section{Experiment and discussion}

To test the robustness of the proposed controller, a $10 \mathrm{~kg}$ weight fixing plate is attached at the end of the link and it was not considered to design control systems. The control parameters used in experiments are tuned to get the highest tracking performances by the trial and error method. In order to evaluate the characteristics of the proposed sliding mode controller, sliding mode controller using the reaching law method are compared. The control laws and their control parameters are expressed as follows:

1) Sliding mode control derived from the reaching law method (RL-SMC)

$u=u_{e q}^{n}+M D s+K s a t(s)$

where

$$
\begin{aligned}
& u_{e q}^{n}=M\left[\ddot{x_{d}}+\Lambda \dot{e}\right]+V+G \\
& \Lambda=\left[\begin{array}{cc}
40 & 0 \\
0 & 30
\end{array}\right], D=\left[\begin{array}{cc}
50 & 0 \\
0 & 110
\end{array}\right], K=\left[\begin{array}{cc}
11 & 0 \\
0 & 3
\end{array}\right], \\
& \phi_{1}=0.123, \phi_{2}=0.350 .
\end{aligned}
$$

2) Sliding mode control derived from the reaching law method with a time-varying sliding surface (TV-SMC)

$u=u_{e q}^{n}+M D s+K s a t(s)$

where

$u_{e q}^{n}=M\left[\ddot{x_{d}}+\dot{\Lambda e}+\dot{\Lambda} e+\dot{\mu}\right]+V+G$ 


$$
\begin{aligned}
& \Lambda_{f}=\left[\begin{array}{cc}
40 & 0 \\
0 & 30
\end{array}\right], D=\left[\begin{array}{cc}
50 & 0 \\
0 & 110
\end{array}\right], K=\left[\begin{array}{cc}
11 & 0 \\
0 & 3
\end{array}\right], \\
& \phi_{1}=0.123, \phi_{2}=0.350, t_{f 1}=t_{f 2}=0.25 \mathrm{~s} .
\end{aligned}
$$

In tuning the sliding mode control to improve the tracking performance, the slope of the sliding surface, the proportional gain, and the switching gain must be increased. But the switching gain cannot be increased much because of chattering. The switching term guarantees the robustness near the sliding surface, but the magnitude of the switching term has a limit. Because of this limit, the transient response under some disturbances is poor. The following experimental results show that the time-varying sliding surface can be one of the solutions to these problems. Fig. 7 shows the step response with a load. The RL-SMC represents the response of the sliding mode control using the fixed sliding surface, and the TV-SMC represents the response of the sliding mode control using the time-varying sliding surface. RL-SMC showed poor transient response. However, TV-SMC can improve the transient response. Fig. 7(a) shows the position responses. The RL-SMC showed large any undershoot and overshoot, but the TV-SMC did not show any undershoot or overshoot. This demonstrates that the TV-SMC can improve the transient response with satisfaction. Fig. 7(b) shows the control inputs. The TV-SMC showed a smaller amount of the control input than the RL-SMC. Fig. 7(c) shows the phase portrait in the phase plane. The TV-SMC showed a smaller locus than the RL-SMC. Fig. 8 shows the position responses with respect to the time-varying interval. The overshoot and undershoot were decreased as the time-varying interval increased, but the response speed was slow. In Fig. 8, the results show much change when the time-varying interval is less than $0.2 \mathrm{sec}$, but they do not show much change when the time-varying interval is larger than $0.2 \mathrm{sec}$. From this fact, the optimal time-varying interval can be selected.

\section{Conclusion}

The excavator is one of the most popular field robots performing various tasks in the field industry. Active research has been devoted to developing an automatic excavator system. In this study, in order to facilitate the development of the automatic excavator system, a miniaturized excavator was constructed. The proposed control hardware is based on two separate personal computers for control and monitoring of the excavator system. In both PCs, communication logics were designed to access each other. The control PC operates either in open loop or feedback control loop mode. Although the developed excavator system is based on the pneumatic circuit, it can function as a viable test-bed since its operating principles are similar to those of a hydraulic excavator. Therefore, the underlying idea of the developed system is applicable to industrial excavators as well as other heavy equipments in industry. Moreover, the sliding mode controller, which has been widely adopted for nonlinear robust control, was built to control each link of the excavator. The performance of the designed control system was evaluated through experiments and showed promising results.



(a) Position of end-effect



(b) Control input 




(c) Phase portrait

[Fig. 7] Step responses with a load



[Fig. 8] Response variations with respect to the time-varying interval

\section{References}

[1] Q. Xiao, Q. Wang, Y. Zhang, "Control Strategies of Power System in Hybrid Hydraulic excavator," Automation in Construction, Vol. 16, Issue 5, pp. 1-7, 2007.

[2] D.C. Gross, K.S. Rattan, "A feedforward MNN controller for pneumatic cylinder trajectory tracking control," International Conference on Neural Networks, Vol. 2, Issue 9-12, pp. 794-799, 1997.

[3] S. Tafazoli, W. S. Clarence, D. L. Peter, "Tracking Control of an Electro hydraulic Manipulator in the Presence of Friction," IEEE Transactions on Control Systems Technology, Vol. 6, No. 3, pp. 401-411, 1998.

[4] B. Song, A. J. Koivo, "Neural Adaptive Control of Excavators," International Conference on Intelligent Robots and Systems, Vol. 1, pp. 162-167, 1995.

[5] Q. P. Ha, D. C. Rye, "Robotic Excavator Swing Control using Fuzzy Rotating Sliding Mode," IEEE International Conference on Fuzzy Systems, Vol. 1, pp. 332-335,

2001.

[6] Y.H. Zweiri, L.D. Seneviratne, A. Kaspar, "Parameter Estimation for Excavator Arm Using Generalized Newton Method," IEEE Transactions on Robotics, Vol. 20, No. 4, pp. 762- 767, 2004.

[7] S. Derek, M. Frank, S. Ian, R. Morrey, "LUCIE the Robot Excavator - Design for System Safety," International Conference on Robotics and Automation, Minnesota, pp. 963-968, 1996.

[8] J. Gu, J. Taylor, D.Seward, "Proportional - Integral-Plus Control of an Intelligent Excavator," Computer-Aided Civil and Infrastructure Engineering, Vol.19, pp. 16-27, 2004.

[9] J.E. Slotine, W. Li, Applied Nonlinear Control, Prentice-Hall International, Inc. 1991.

Jeongju Choi



$<$ Research Interests $>$

Automatic excavator system, Artifical Intelligent control 